\title{
Representatividade no relato de si e reconhecimento do outro: Transativismo e humanização multimídia transmasculina
}

\author{
Deivid Nascimento de Carvalho \\ Recebido em março de 2021 \\ Aceito em junho de 2021
}

\begin{abstract}
RESUMO
Este artigo tem por objetivo tecer reflexões sobre a representatividade que pessoas transgêneras do espectro masculino possuem nas mídias. Primeiramente, foi realizada uma observação etnográfica através de mídias digitais transmasculinas e, posteriormente, houve anexo da literatura acadêmica sobre a temática. O transativismo, a representação identitária e o relato de si são, por sua vez, recursos de visibilidade para demandas sociais e políticas de pessoas transgêneras nas mídias. Deste modo, a comunicação contra-hegemônica e produção de conhecimento qualificado sobre transidentidades contribuem para sua humanização nas multimídias, sejam mídias digitais, redes sociais e internet, seja publicidade e propaganda, televisão, literatura científica e qualquer outro mecanismo linguístico. $\mathrm{O}$ relato de si publiciza a travessia que muitos transhomens vivenciam em suas marcas resilientes. Mediante este relato, quem o recebe tem, por outro lado, o reconhecimento destas marcas na identificação de trajetórias em comum. A representatividade, portanto, é um itinerário que possibilita indivíduos solitários e vilipendiados a seguirem uma travessia em conjunto.
\end{abstract}

Palavras-chave: Representatividade; Transativismo; Transmasculinidade; Mídia.

\section{Representativeness in self-report and recognition of the other: Transactivism and transmasc multimedia humanization}

\begin{abstract}
This article aims to reflect on the representativeness that transgender people of the male spectrum have in the media. First, an ethnographic observation was carried out through transmasculine digital media and, later, there inclusion the academic literature on the subject. Transactivism, identity representation and self-reporting are, in turn, visibility resources for social and political demands of transgender people in the media. Thus, counter-hegemonic communication and the production of qualified knowledge about transidentities contribute for humanization of these identities in multimedia, be it digital media, social networks and the internet, be it advertising, television, scientific literature and any other linguistic mechanism. The narrative discloses the journey that many transmasc experience in their trajectories. Through report, whoever receives it has, on the other hand, the recognition of these marks in the identification of common trajectories. Representativeness is, therefore, an itinerary that allows individuals who are lonely and vilified to hold a crossing together.
\end{abstract}

Keywords: Representativeness; Transactivism; Transmasculinity; Media;

\footnotetext{
'Bacharel em Antropologia - Diversidade Cultural Latino-Americana na Universidade Federal da Integração Latino-Americana (UNILA, PR), 2021. Pesquisador sobre antropologia das emoções, gênero e sexualidade. Documentarista e produtor audiovisual. E-mail: deividncarvalho@outlook.com.
} 
Este artigo foi inspirado na representatividade transgênera em espaços de poder. Aqui, determino que estes espaços midiáticos são relacionados ao poder imagético e discursivo, onde estes indivíduos inserem suas trajetórias de modo a compor um relato sobre si na representação de uma bandeira político-social que visa o tensionamento de políticas públicas de inclusão, de respeito à dignidade e combate à violência que marcam a caminhada destes sujeitos que lutam para sobreviver em um país altamente transfóbico. O relato de si ecoa a voz historicamente calada, cuja fala centrava-se apenas na cisgeneridade. $\mathrm{O}$ papel midiático que estes indivíduos estão inseridos transformam a readaptação da autobiografia para emergir reflexões sobre os encontros e desencontros da identidade através de um questionamento de si perante o mundo. Desta forma, a produção de conteúdo nas mídias sociais são ferramentas de articulação política, tal como a produção de debate e autoconhecimento educativo sobre a pauta transgênera, para introduzir visibilidade à diversidade, tanto nas mídias digitais quanto no reflexo da mídia em ambientes tradicionais, como publicidade, televisão, cinema, entre outros.

Este artigo, por sua vez, foi inspirado em meu trabalho de campo realizado durante o fim de minha graduação em Antropologia, Diversidade Cultural LatinoAmericana (2020). Neste período, acompanhei 100 perfis multimídias ${ }^{2}$ de produção de conteúdo produzido por homens transgêneros e identidades do espectro masculino na influência midiática da publicidade e internet. Foi realizada uma observação etnográfica, cujo olhar determina o ouvir e o escrever, conforme o antropólogo Roberto Cardoso de Oliveira (2000). Embora este artigo seja fruto de uma observação etnográfica, não houve intromissão ou interferência nos perfis observados. Entretanto, a escrita desses relatos demandam uma transcrição desta etnografia observada, mediando, por sua vez, a intromissão e interferência. Deste modo, não haverá

\footnotetext{
2 São materiais de estudo neste artigo: publicações públicas de homens trans/transmasculinos nas mídias sociais/digitais como perfis de Instagram, canais de Youtube, podcasts no Spotify, grupos e páginas de Facebook, blogs no Twitter, além de conteúdos da grande mídia hegemônica e da mídia alternativa contra-hegemônica sobre temas relacionados a transmasculinidade. Esta observação etnográfica ocorreu entre 2018 e 2020.
} 
exposição pública destes perfis, nem informações que possam identificar os interlocutores. Todos os perfis observados são públicos, pois, a produção destes conteúdos visam a publicação massiva destes recortes privados em publicização de si nas mídias digitais. A busca de influência nestes espaços é, sobretudo, um discurso de poder contra-hegemônico que estes homens trans utilizam para demarcar território e erguer a bandeira do orgulho enquanto resilientes de trajetórias que, compulsivamente, invisibilizam seus corpos e identidades.

$\mathrm{Na}$ produção deste artigo, assim como na metodologia de meu TCC, está presente a observação etnográfica de mídias sociais e digitais de homens transgêneros e identidades transmasculinas. Mídia Social é uma produção de conteúdo nas redes sociais (fotos, vídeos, blog, etc) divergente da produção de conteúdo da mídia tradicional (televisão, rádio, jornal, etc). No entanto, a Mídia Digital diz respeito aos espaços tecnológicos de comunicação, assim como um conjunto de veículos que promovem a comunicação digital através de aplicativos e plataformas midiáticas. Para tanto, utilizo mídias sociais e mídias digitais como sinônimos, a fim de exemplificar a linha tênue entre ambos conceitos da comunicação social. As mídias digitais, assim como o desenvolvimento tecnológico, emolduram uma nova linguagem para comunicar a influente dinâmica cultural informativa, no compartilhamento de conteúdo e influência de consumo na visibilidade do mercado, na divulgação de produtos e serviços, bem como na difusão de conhecimento para transformação social através da educação e reflexão.

Para tanto, este artigo visa tecer, de modo breve, como a emergência destes conteúdos produzidos por homens trans/transmasculinos são capazes de influenciar a dinâmica de um transativismo político nas multimídias. Utilizo este termo pois, embora a metodologia centralize-se na mídia social/digital, há de se considerar que a influência destes conteúdos atravessam uma convergência multimidiática entre diversas plataformas de mídias, sejam tradicionais ou digitais. $\mathrm{O}$ alcance midiático influencia no comportamento do espectador que acompanha estes canais comunicacionais. Muitos transhomens adentram esses canais para propor visibilidade, para demarcar diálogos diante do entretenimento, a fim de desmascarar conteúdos precários acerca da imagem trans promovida pela mídia tradicionalista. Portanto, 
utilizam-se da comunicação contra-hegemônica em espaços midiáticos que contribuem para que estes sujeitos permaneçam invisíveis frente à inclusão sociopolítica de suas identidades.

Deste modo, a psicanalista Letícia Lanz nos elucida a ideia de que uma pessoa não se torna homem e mulher por ter nascido macho ou fêmea, mas por se reconhecer e se identificar com o modelo socialmente pré estabelecido do que é homem ou mulher, e esta identificação acontece independentemente do sexo genital (LANZ, 2015). Para tanto, o gênero se compõe enquanto norma socialmente compulsória e, por outro lado, está sujeito a escolhas individuais ou coletivas em distintas épocas e contextos sociais. Seguindo Lanz, ser transgênero não significa, portanto, que seja instaurada uma nova categoria identitária de gênero, entretanto, condiz com uma nova condição sócio político-cultural que transgride normas e regras do sistema sexo/gênero. Isto é, uma identidade transgênera reluz a um gênero divergente das concepções de masculino/feminino e homem/mulher. Por este motivo, neste artigo, utilizo o termo transgênero para designar indivíduos que rompem com o dispositivo binário de gênero, de modo a incluir para o debate as demais transidentidades.

Este é um termo "guarda-chuva" que acolhe representações identitárias de gênero divergente, conhecido como o $T$ da sigla LGBT (Lésbicas, Gays, Bissexuais, Travestis, Transexuais e transgêneros). No Brasil, assim como pontuado por Lanz (2015), este não é um termo popularmente utilizado e, desta forma, as transidentidades seguem suas representações autônomas, como transexual ou travesti. Além disso, é muito comum lermos em noticiários da mídia o termo transgênicos que, por sua vez, demonstra falta de conhecimento sobre este assunto. É interessante notar que o termo transgênero inclui diversas identidades trans, sejam elas travestis, pessoas nãobinárias, transfemininas, transmasculinos, entre outras, e dispõem de um termo que acolhe transidentidades em suas diversas identificações.

Atualmente, o termo LGBTQIAP+ tornou-se amplamente utilizado para se referir a Lésbicas, Gays, Bissexuais, Trans, Queer, Intersexo, Assexuais e Pansexuais, de modo a propor maior visibilidade para identidades de gênero e sexualidade, em benefício da diversidade da sigla. Para tanto, este texto está vinculado à visibilidade autobiográfica na reinvenção da identidade e intimidade de homens trans/masculinos, 
isto é, identidades transgêneras que se identificam no espectro masculino. Ao longo do texto, utilizo termos de reconhecimento equivalentes, como transhomem, homem transgênero, transmasculino, para inclusão à diversidade de identificações do masculino. O relato de si nas mídias digitais e a representatividade multimídia contribui para que suas trajetórias sejam visíveis sob o olhar público de suas identidades. A representação e a humanização das mídias na inclusão da temática transgênera transformam a vida destas pessoas que se sentem, constantemente, vilipendiadas frente a violência que as tornam indignas de comoção coletiva.

\section{Relatos de si e reconhecimento do outro}

No Brasil, o marco representativo de homens trans, em caráter nacional, foi instaurado na organização e fundação da Associação Brasileira de Homens Trans (ABHT) em 2012. Em 2013, o Instituto Brasileiro de Transmasculinidades (IBRAT), em certa medida, ocupou o lugar do ABHT após conflitos internos e redução da atividade dos organizadores. No aspecto descritivo de emergência desses movimentos sociais, no ativismo e organizações políticas institucionalizadas por transhomens, a pesquisadora Simone Ávila (2014) e o cientista político Thiago Coacci (2018) pontuaram, de forma detalhada, o surgimento de instituições político-sociais transespecíficas formuladas por e para esta população. Além disso, Coacci (2018) entrevistou transativistas e acompanhou os desdobramentos institucionais em prol de políticas públicas para travestis, transexuais e transgêneros, seja na inclusão social, no combate a violência e discriminação, seja na visibilidade de pautas emergentes. Ademais, pesquisou a produção de saberes contra-públicos 3 fomentados em conhecimentos precários sobre estas identidades, tanto na qualidade de informações quanto no mapeamento

\footnotetext{
3 "Esses conhecimentos estão, geralmente, ancorados em posições subalternas e oferecem uma espécie de contra-discurso ao discurso do público oficial. Dessa maneira, os conhecimentos contra-públicos ao serem produzidos, fomentados ou divulgados pelos movimentos sociais se dirigem aos próprios ativistas que integram o campo do movimento social em questão e os grupos que esses dizem representar, oferecendo uma narrativa alternativa que permite formular e responder de outras maneiras questões sobre suas identidades, seus objetivos, suas condições no mundo, seus interesses. Esses conhecimentos ainda se dirigem a um público mais amplo, disputando a legitimidade, a neutralidade, a correção ou a objetividade dos conhecimentos considerados precários" (COACCI, 2018, p. 30).
} 
estatístico do grupo. Desta maneira, autor elabora uma síntese do ativismo e, por sua vez, as ondas do movimento transgênero no Brasil:

\begin{abstract}
A primeira percorreu do início dos anos 1990 até o início dos anos 200o. Foi um período marcado principalmente pelo surgimento dos primeiros grupos organizados de ativismos travesti, como a ONG pioneira ASTRAL, no Rio de Janeiro. A segunda onda ocorreu entre os anos de 2000 e 2010. Foi marcada, dentre outras coisas, por uma expansão do movimento por todo o país, pelo fortalecimento das relações com o Estado em âmbito nacional e o surgimento das primeiras políticas públicas, como o Processo Transexualizador. Há ainda o surgimento de forma mais coesa de um campo de estudos sobre transexualidade no Brasil, intimamente relacionado com a expansão do processo transexualizador. A terceira onda ocorre nos anos de 2010. Foi um período bastante conturbado e conflituoso, não apenas para o campo do movimento, mas para o contexto nacional mais ampliado. Foi marcado por uma expansão ainda maior do movimento, pela multiplicação dos modos de organização, de ação e identificação, bem como pela visibilidade cada vez maior da população trans na mídia e nas produções acadêmicas (COACCI, 2018, p. 245).
\end{abstract}

Como notado por Coacci (2018), Amorim (2016), Ávila (2014), Freitas (2014), Nery e Maranhão (2013), há um movimento emergente de autoafirmação entre transhomens, tanto na mídia quanto nas produções acadêmicas e biográficas. As produções autobiográficas são relatos pessoais que falam sobre si. Se anteriormente estavam centralizadas na literatura, nos dias atuais estão visibilizadas em plataformas cibernéticas de compartilhamento de informações, sintetizadas nas mídias digitais e em novos modos de sociabilização on-line e off-line. As redes sociais, antes de se estabelecerem enquanto espaços de sociabilização, são, sobretudo, espaços de articulações políticas. Influentes de uma comunicação contra-hegemônica, produção de conteúdo autoral, são formadores de opinião baseados na liberdade de expressão. A autenticidade de informações publicadas nestas redes interpessoais são realizadas mediante exposição publicizada de si ou, por outro lado, no anonimato que resguarda a identidade pública.

O psicólogo Alexandre Amorim (2016) realizou sua pesquisa em dispositivos de confissão mediados por transhomens, com base em Michel Foucault, sobre o relato de si através de blogs. Para tanto, "em momentos de solidão, a escrita seria um possível olhar capaz de constranger e revelar o que se passa no interior das pessoas" (AMORIM, 2016, p. 158). Os blogs são dispositivos de escrita que permitem o compartilhamento de 
narrativas particulares, organização de relatos e confissões de sua trajetória, um modo de refletir sobre si a partir de suas experiências. Na produção destes relatos publicizados ocorrem a autodescoberta, a reflexão e aprendizado. Há possibilidades de socialização promovidas pela visibilidade destes relatos, a identificação e constante troca entre o público e o privado.

\begin{abstract}
Os blogs são um palco de muitos eventos e espetáculos. Constituem um importante lugar de experimentações, pois esse é um lugar que permite que os transhomens possam falar, ou melhor, possam escrever sobre si, suas opiniões e seus sentimentos sem ter medo do que a sua família vai achar, sobre o que os seus amigos vão pensar deles ou sobre o que a sociedade vai concluir a partir daquilo. Aquilo que poderia ser motivo de vergonha tornar-se um motivo que os conectam a outras pessoas, passa a ser um motivo de compartilhamento. Compartilhar suas histórias é um exercício que confere sentidos a tantas dores e rotinas difíceis. Pode-se perceber que essas histórias são contadas com uma expectativa de que alguém as leia, tornando os blogs também um lugar pela busca de um olhar de reconhecimento, que atribua sentido à vida de quem conta sua história (AMORIM, 2016, p. 163-164).
\end{abstract}

Como menciona o autor, os Blogs configuram a exposição de si sob o armário de vidro das mídias digitais, na alusão metafórica da identidade trancada no armário, cuja manutenção de "segredos" são internalizados em um lugar "seguro" para si mesmo. Há grande tendência destes sujeitos ao isolamento social para preservar o sofrimento. A repressão interior, por muitas vezes, está relacionada com o medo da vulnerabilidade, na busca da auto identificação. Esconder-se de si mesmo se torna sinônimo de proteção. O relato de si fomenta o autoconhecimento e aflora a descoberta da identidade. A auto análise se faz um dos componentes fundamentais para a construção identitária. Para Judith Butler (2015a): “o universal não só diverge do particular; essa divergência é o que o indivíduo chega a experimentar, o que se torna para o indivíduo a experiência inaugural da moral” (p. 11). Para tanto, "o 'eu' volta-se contra si mesmo, desencadeando contra si mesmo uma agressão moralmente condenatória e, com isso, inaugura-se a reflexividade” (BUTLER, 2015a, p. 11).

Conforme considerações de Butler (2015a), a moral reproduz normas e regras, cabe ao sujeito entendê-las para questioná-las. No entanto, embora haja o entendimento da moral na elaboração do sujeito, não há o desprendimento total da moral no relato de si, pois, o sujeito permanece incluso estruturalmente neste conjunto 
de normas e regras. Desta forma, há de se negociar estas normas e regras instauradas de forma reflexiva: "relatamos a nós mesmos simplesmente porque somos interpelados como seres que foram obrigados a fazer um relato de si mesmo por um sistema de justiça e castigo" (BUTLER, 2015a, p. 12). Desta maneira, um relato de si depende de um questionamento elaborado por alguém e este questionamento pode estar vinculado a estrutura moralmente condenatória ou permissiva das normas e regras ordenadas na composição do sujeito. Se ocorre um relato de si, significa, portanto, que há um questionamento realizado por alguém e neste convencionalismo ocorre uma dualidade entre "quem verdadeiramente sou" e "o que querem saber de mim." Então, será descrito um eu que reconstrói suas ações a ponto de solucionar um questionamento que, por sua vez, busca determinado objetivo. É neste contexto que ocorre a dinâmica do relato de si mesmo (BUTLER, 2015a, p. 12).

Contudo, a filósofa nos demonstra que o questionamento elaborado pelo outro também pode estar relacionado à vontade de saber para conhecer e aprender, distanciando-se da interrogação punitiva do moralismo condenatório. O silêncio frente a indagação pode se estabelecer como um questionamento voltado para o questionador e para a dúvida formulada, dado ao caráter equivocado da autoridade de quem interroga. Além da relação de poder entre quem interroga e quem se justifica, o silêncio pode anular a autonomia do questionador para com o questionado. A recusa do relato de si mesmo não deixa de ser um relato de si, nem se anula enquanto discurso. $\mathrm{O}$ ato de relatar a si é proposto por uma narrativa que possui o objetivo de inferir um discurso sobre uma história de vida individual fomentada pelo interesse público. A mediação entre o discurso público sobre experiências da vida privada invade um conjunto de referências moralistas que incidem sobre o indivíduo que faz o relato e promulga uma constante condenatória. Desta maneira ocorre a tônica entre o eu e a moral. Assim se estabelece uma relação sobre quem fala e para quem se fala.

Não obstante, Butler (2015a) nos mostra que a busca pelo autoconhecimento é cercada a partir do que é permitido ser dentro dos modos inteligíveis de representar a si, permeado por um conjunto de normas e regras que permitem o que é ou não legitimado como autoidentificação. Esse conjunto de normas e regras determinam ações efetivas de controle para legitimar a identidade do sujeito. No entanto, a 
construção da identidade, antes de tudo, depende de decisões sobre si mesmo, são escolhas pontuais. O modo pelo qual se sobressai a produção do sujeito em normas e regras limitantes transforma o relato de si em um discurso de poder. E isso qualifica a verdade sobre si, cujo relato requer o questionamento sobre "quem eu sou" e se há questionamento deste conjunto de normas e regras estruturais, há, por sua vez, o questionamento de si diante da descrição do relato. Se questiono a produção do ser e, em certa medida, sou questionado diante de um relato de mim mesmo, primeiramente, sou questionado por mim.

Estas provocações elaboradas por Judith Butler (2015a) são fundamentais para entender a produção de conteúdo realizada nesta pesquisa. São essenciais para compreender a vida de sujeitos que se utilizam da autobiografia, de narrativas e relatos sobre si para demarcar a verdade sobre seus corpos, trajetórias e caminhos de vida. Remetem a produção contra-público formulada por Coacci (2018), simbolizando o rompimento de conhecimentos precários de indivíduos subalternizados diante de relações de poder, cuja legitimidade de si subverte o saber hegemônico. São identidades pautadas em escolhas, auto identificação e constante construção de si. São compartilhamentos de experiências que remetem a uma cultura de confissões para compreender-se integralmente à luz da negação estrutural de seus corpos. $\mathrm{O}$ discurso sobre gênero e sexualidade, a construção do corpo, denúncias de violências e repressões sociais, a discriminação de suas identidades, as rotinas de exames e atendimento dos profissionais de saúde, bem como comportamentos, socializações e hormonização são relatos que transformam debates em ambientes informativos sobre transgeneridade e suas ramificações. Para tanto, “o que fica expresso nas escritas é a satisfação de encontrar outros transhomens para compartilhar suas vivências singulares ali naqueles encontros pontuais no ambiente virtual” (AMORIM, 2016, p. $172)$.

Neste sentido, Butler (2015) nos relembra que o relato de si simboliza a tônica de conhecer a si mesmo e, por sua vez, reconhecer o outro. O relato está intrinsecamente relacionado à visibilidade de vivências e no protagonismo de histórias que, por muitas vezes, não são contadas ao público. Não são publicizadas e são negligenciadas sem a devida importância. Sobretudo, por sujeitos que são 
historicamente marginalizados e subalternizados, cujas vozes não possuem alcance diante de mecanismos de manutenção de poder. A produção de relatos sobre si forma um espaço autobiográfico contra-hegemônico que se contrapõem aos modelos dominantes de normas e regras socialmente compulsórias no âmbito estrutural. São saberes plurais que demarcam a subversão do silenciamento de suas experiências de vida. A descoberta da transexualidade, por outro lado, pode ser mediada por espaços que propõem o compartilhamento de transexperiências. São debates e rodas de conversa, organizações e instituições LGBTQIAP+, ambientes culturais e artísticos, produções cinematográficas, fotográficas e literárias, programas de TV e entrevistas, sites e redes sociais. São espaços, portanto, que permitem o aprendizado e a publicização de si.

\section{Representatividade e humanização das mídias}

Repensar sobre gênero e sexualidade através da projeção de imagens, representações estéticas e personificações retratadas no cinema, fotografia, artes plásticas, literatura, ou seja, elementos artísticos, neste exemplo, denotam um espaço de produção de identidade. Deste modo, pessoas transgêneras se reconhecem e interpretam signos na decodificação subjetiva de seus corpos e identificações. Representações socialmente construídas sobre o masculino e feminino determinam normas compulsórias de identidades legitimadas estruturalmente. A representatividade na arte contrapõe, por muitas vezes, espectros construtivos binariamente heterocentrado embora, em diversos casos, são a súplica contraditória da transidentidade que se torna "exótica" mediante espetacularização cultural. São sujeitos que estão constantemente associados ao conhecimento precarizado de suas identidades. Este estima social corrobora para desinformação, patologização 4 e hostilização sobre indivíduos marginalizados.

\footnotetext{
${ }^{4}$ Em 2018, a transexualidade deixou de ser considerada um transtorno mental, pois era integrada à Classificação Internacional de Doenças (CID) da Organização Mundial de Saúde (OMS). Ocupava a lista de "transtorno de identidade de gênero". Isto é, tratavam-na como "transsexualismo", cujo sufixo "ismo" denota patologia aplicada pelo saber/poder médico. Na decisão da OMS, embora não seja considerada patologia, a transexualidade integra um novo capítulo do CID como "incongruência de
} 
A transexualidade é "descoberta”, por muitas vezes, através de um filme, leitura de livro, pesquisas na internet, redes sociais, identificação com algum personagem ou inspiração na história de vida de algum transgênero. A comunicação de massa possui papel fundamental na formação de opinião da transexualidade, principalmente, da década de 1980 para os dias atuais. A representação, em muitos casos, está marcada na massificação do espetáculo e sensacionalismo centralizado na “mudança de sexo". Na sexualização de corpos trans como “fantoches sexuais” e exímia construção da feminilidade ou masculinidade transgênera enquanto parâmetro legítimo da "transexualidade verdadeira", configurada na semelhança "cisgênera" da identidade trans binária. Frequentemente, o corpo trans é visto como sinônimo de aberração, bestializado em sua figuração, sexualizado por órgãos reprodutores e associado à doente mental. São regalias históricas do saber/poder médico na patologização do "transexualismo" equivocado, contudo, provocativo pelo conservadorismo religioso, fundadores da moral e dos "bons costumes". São discursos políticos que provocam violência, naturalizam o índice de assassinatos e a precarização estigmatizada destes sujeitos. Conforme Guy Debord (2003):

O espetáculo, compreendido na sua totalidade, é ao mesmo tempo o resultado e o projeto do modo de produção existente. Ele não é um suplemento ao mundo real, a sua decoração readicionada. É o coração da irrealidade da sociedade real. Sob todas as suas formas particulares, informação ou propaganda, publicidade ou consumo direto de divertimentos, o espetáculo constitui o modelo presente da vida socialmente dominante. Ele é a afirmação onipresente da escolha já feita na produção, e o seu corolário o consumo. Forma e conteúdo do espetáculo são, identicamente, a justificação total das condições e dos fins do sistema existente. O espetáculo é também a presença permanente desta justificação, enquanto ocupação da parte principal do tempo vivido fora da produção moderna. [...] A sociedade que repousa sobre a indústria moderna não é fortuitamente ou superficialmente espetacular, ela é fundamentalmente espetaculosa. No espetáculo, imagem da economia reinante, o fim não é nada, o desenvolvimento é tudo. O espetáculo não quer chegar a outra coisa senão a si próprio (DEBORD, 2003, p 15-18).

Para tanto, reflete Butler (2011) acerca do esvaziamento humano promovido pela mídia:

gênero". Neste caso, está relacionada à demanda que pessoas transgêneras possuem ao atendimento transespecífico, sobretudo, no que diz respeito ao acolhimento psicológico, reposição hormonal e intervenções cirúrgicas no sistema público e privado de saúde. 
O processo de esvaziamento do humano feito pela mídia por meio da imagem deve ser entendido, no entanto, nos termos do problema mais amplo de que esquemas normativos de inteligibilidade estabelecem aquilo que será e não será humano, o que será uma vida habitável, o que será uma morte passível de ser lamentada. Esses esquemas normativos operam não apenas produzindo ideais do humano que fazem diferença entre aqueles que são mais e os que são menos humanos. [...] Mas muitas vezes esses esquemas normativos funcionam precisamente sem fornecer nenhuma imagem, nenhum nome, nenhuma narrativa, de forma que ali nunca houve morte tampouco houve vida (BUTLER, 2011, p. 28).

Por outro lado, multimídias, produções artísticas e projeções de imagens subversivas do estigma de marginalização são, todavia, construtoras de subjetividades, emanam a imaginação e reflexão, atingem camadas do subconsciente, afloram emoções, sensações internalizadas e escondidas. Acolhem memórias afetivas, fragmentam lembranças, reconstroem suposições, desmistificam preconceitos, incentivam a inclusão social. Provocam o relato sobre si e sobre o outro, reflexos de identificação e representação. A arte possui poder de transformar vidas, dispõe reflexividade e subjetividade. A inclusão de vidas transgêneras em veículos artísticos e midiáticos, sobretudo, narrativas que subvertem conhecimentos precarizados, transformam histórias reais em dramaturgia. Principalmente, por retratar espelhos discursivos sobre a transexistência. Elabora, por sua vez, a humanização do indivíduo trans para além das telas, como integridade constituidora de carácter social. Revela a tônica de aproximação e acolhimento de sujeitos que, por vezes, se sentem solitários, incompreendidos e reprimidos. A humanização da imagem recai aos indivíduos vilipendiados à luz do dia, comumente vistos como indignos de comoção pública.

Em contrapartida, há debates sobre a representatividade trans estar centralizada nas mãos de pessoas cisgêneras. Na contribuição do desfoque de pessoas trans, na impossibilidade de serem representadas por si mesmas, principalmente, como detentoras de suas narrativas, na ocupação de espaços demarcados pela negação de suas identidades. No cinema, teatro e televisão, por exemplo, a atuação de filmes e séries, frequentemente, são compostas de personificações de homens cisgêneros interpretando mulheres trans e travestis, enquadradas no estigma social precarizado de "homem vestido de mulher" para configurar uma identidade transfeminina. $\mathrm{O}$ viés do 
debate não é, por sua vez, a censura da arte na composição da personagem, mas a proposta de inclusão social de mulheres trans e travestis, bem como homens trans e outras identidades transgêneras na posse de suas identidades humanizadas pela mídia. Um lugar político de existência e sobrevivência, a incessante busca pela legitimidade de relatar a si mesmo para fomentar o reconhecimento do outro. Simboliza a luta política de subversão do estigma social marginalizado. Não obstante, a cultura transgênera é, portanto, historicamente fundamentada por pessoas cisgêneras, nas regalias do dispositivo binário de gênero heteronormativo.

A visibilidade proporcionada pela representatividade social relembra o ditado “quem não é visto, não é lembrado" para tensionar instâncias governamentais, políticas públicas e direitos de igualdade entre transgêneros e cisgêneros. Além de proporcionar maior debate sobre identidades e diferenças no âmbito político, social e cultural de nossas representações. Um debate tão caro e tão importante. É uma maneira de combater a desigualdade e violência para promover dignidade aos rostos indignos de empatia. A proposta da comunicação contra-hegemônica implica em problematizar e subverter o conhecimento pautado, sobretudo, nos modelos dominantes. Neste âmbito, significa democratizar a mídia para dar voz à pluralidade de saberes e representações culturais que demarcam a descolonização das relações de poder. No que se refere a construção do dispositivo de gênero, dominação masculina e, também, hierarquização, segregação e classificação social. A mídia, eventualmente, possui o papel de construir opinião e reafirmar condutas morais através do sensacionalismo entre o sujeito que merece uma condição humana e aquele que, por sua vez, se torna uma ameaça generalizada. Com base no filósofo Emmanuel Levinas, Judith Butler nos demonstra:

Quando consideramos as formas comuns de que nos valemos para pensar sobre humanização e desumanização, deparamo-nos com a suposição de que aqueles que ganham representação, especialmente autorepresentação, detêm melhor chance de serem humanizados. Já aqueles que não têm oportunidade de representar a si mesmos correm grande risco de ser tratados como menos que humanos, de serem vistos como menos humanos ou, de fato, nem serem mesmo vistos. Temos um paradoxo diante de nós, pois Levinas deixou claro que o rosto não é exclusivamente um rosto humano e, mesmo assim, é uma condição para a humanização. Por outro lado, há o uso do rosto, no interior 
da mídia, no sentido de efetivar a desumanização. Poderia parecer que a personificação nem sempre humaniza (BUTLER, 2011, p. 24).

Em Vidas Precárias (2011), Butler nos incita a provocações acerca da desumanização midiática, fundamentada por corporações que monopolizam as relações de poder da mídia hegemônica sob controles tendenciosamente políticos, conservadores e religiosos. Deste modo, há jogos de interesse sobre o que será reconhecido enquanto legitimidade e o que será, por outro lado, menosprezado, não noticiado e sem devida importância:

A exigência por uma imagem mais verdadeira, por mais imagens, por imagens que comuniquem todo o terror e realidade do sofrimento tem seu lugar e importância. O apagamento daquele sofrimento por meio da proibição de imagens e representações geralmente circunscreve a esfera da aparência, daquilo que podemos ver e daquilo que podemos saber. No entanto, seria um erro pensar que apenas precisamos encontrar as imagens certas e verdadeiras e que, dessa maneira, certa realidade será exprimida. A realidade não é exprimida por aquilo que está representado no interior da imagem, mas sim por meio do desafio à representação que a realidade entrega (BUTLER, 2011, p. 28).

Neste parâmetro, temos o levantamento realizado por Coacci (2018) que dialoga à ausência de informações sistematizadas demograficamente entre a vida e morte de travestis, transexuais e demais transgêneros enquanto grupo socialmente marginalizado, em violências silenciadas pelo Estado. Desta maneira, noticiários e mídias em geral, retratam identidades trans de forma banalizada, usurpadas de uma imagem humanizada. Por conseguinte, não tecem informações a respeito do índice de mortes do país que mais assassina travestis e transexuais no mundo, conforme dados da Associação Nacional de Travestis e Transexuais (ANTRA). Quando publicizado, não há respeito da identidade de gênero da vítima. Há exposição do nome de registro e, portanto, os requintes de violência padecem na morte e vida: "Eles não mostram violência, mas há uma violência na moldura do que é mostrado. Esta violência é o mecanismo por meio do qual certas vidas e certas mortes permanecem não representadas" (BUTLER, 2011, p. 29). 


\section{Dispositivos de confissões e representatividade transmidiática}

Para Foucault, a confissão é uma técnica de si, o indivíduo produz uma relação consigo mesmo, com seus pensamentos e conduta, pois: "somos coagidos, somos condenados a confessar a verdade ou a encontrá-la" (FOUCAULT, 1999, p. 29). Este artigo, portanto, está centralizado na autobiografia de pessoas transmasculinas, cujo rosto humanizado se faz representativo na pluralidade de itinerários compartilhados nas mídias digitais. É neste espaço que os sujeitos transgêneros inserem suas narrativas através de experiências e mobilização social para que a humanidade de seus corpos estejam legíveis ao público que recebem estes relatos. O roteiro encenado da desumanização transmidiática atribui patologia, espetacularização e violência demarcada na precarização do conhecimento transgênero instaurado pela sociedade heterocentrada, no papel de anormalização e bestialização destes sujeitos vilipendiados à luz do dia. A construção deste conhecimento contra-público simboliza a ruptura desta narrativa marcada pela precariedade do olhar desumano sob o rosto sistematicamente desamparado. Por este motivo, este artigo está centrado na trajetória autobiográfica transgênera pois, embora os recortes biográficos sejam individuais, há de se demarcar este relato de si mesmo no reconhecimento do outro. $\mathrm{O}$ ato de falar sobre si, na ruptura da voz que não dispõe um espaço humanizado, sobretudo, faz ecoar a voz calada diante da multidão. A humanização transgênera nas mídias acompanha, intrinsecamente, as dinâmicas do regime de visibilidade. Conforme Simone Ávila,

\footnotetext{
Um regime de visibilidade prevê uma reordenação dos modos de ver e de ser visto em um mesmo movimento nos dispositivos de vigilância, os quais são cada vez mais diversos em suas técnicas, modos de atuação e significação. [...] O 'espaço biográfico' composto por autobiografias trans, documentários, entrevistas, mídias digitais e televisivas e redes sociais virtuais têm se constituído como modos de visibilidade de transhomens, no qual não só circulam diferentes discursos sobre ser trans como também os ressignificam (ÂVILA, 2014, p. 145-176).
}

No espaço midiático, há reconstrução da imagem a ser enunciada como formadora de opinião, na capacidade de influenciar e atingir pessoas, na captação de 
massa. A representatividade e a introdução de pessoas transgêneras frente essas categorias de poder inauguram a possibilidade de identidades trans possuírem autonomia para exercerem um papel de visibilidade sobre suas existências, trajetórias e culturas. A utilização destes espaços subvertem as relações de poder que asseguram a desumanização desses sujeitos afins da exímia conservação transfóbica de bestialização e massificação da precariedade trans. Falar sobre a própria narrativa, utilizando-se do mesmo recurso de poder que manipula a precariedade é, ao mesmo tempo, insubordinar o controle monolítico do discurso dominante. Sintetiza, por sua vez, a abertura de caminhos para que a pluralidade de falas deturpem a dominância da imagem precarizada, no advento da representatividade do relato de si para a representação do outro.

Neste espaço biográfico, os relatos sobre si transformam o conhecimento precário (COACCI, 2018) em narrativas contra-hegemônicas, dando luz à representação de si diante do compartilhamento de experiências que visam fomentar informação e humanização de seus corpos e identidades. No que tange às transmasculinidades, assim como detona Guilherme Almeida (2012), há uma dualidade entre a exposição de si e a invisibilização da identidade para a "preservação" da transgeneridade em espaços públicos, embora a influência representativa de homens trans seja um fator determinante para maior entendimento social do sujeito na popularização de rostos transmasculinos diante das multimídias.

\footnotetext{
Em outras palavras, o uso da testosterona no caso dos homens trans, ao contrário do que ocorre com as mulheres trans, torna-os bastante próximos fisicamente às expectativas sociais de como deve parecer um homem, o que contribui para invisibilizá-los. Essa invisibilidade adquirida com frequência a duras penas significa para a maior parte um agradável momento de trégua na estressante e contínua batalha por respeito à identidade/expressão de gênero. O fato de o público não saber, por um lado, possibilita práticas de camuflagem social que favorecem o conforto e o acesso individual a direitos. Por outro lado, principalmente na visão do ativismo, isso prejudica a luta coletiva, inviabiliza o reclame por direitos e faz com que as mulheres trans se sintam solitárias (ALMEIDA, 2012. p. 519).
}

A influência que homens transgêneros e identidades transmasculinas possuem nas mídias demarcam a popularização de uma identidade transgênera no espectro masculino, na representatividade de masculinidades trans inseridas na diversidade 
LGBTQIAP+. A representação destes rostos inserem a pluralidade de nuances do masculino, que dissolve a cultura de masculinidade nociva como semblante compulsório do ser/reconhecer masculino. Na publicidade, emanam a influência de consumo, onde pessoas trans são vistas enquanto dignas de provocar o consumismo, incentivar o consumo sobre determinado produto, assunto ou estilo de vida. $\mathrm{Na}$ televisão, compartilham sobre sua trajetória, de modo a causar orgulho, comoção pública ou empatia sobre as raízes que os mantém resilientes de tantas caminhadas em busca de si. Na internet, no poder influente, são produtores de conteúdo sobre seus itinerários, sobre marcas que carregam admiração pela construção de si mesmo e por denúncias de uma sociedade que insubordina oportunidades de vida, cujas portas das escolas, universidades e mercado de trabalho são, costumeiramente, fechadas.

É interessante mencionar que as mídias sociais e o discurso influente da internet são emergentes, sobretudo, se compararmos à instauração da cultura de massa com a imagética discursiva da televisão na metade do século XX. A dialética do discurso emoldurado na argumentação enquanto componente formador de opinião, na antítese da massificação da informação receptiva, isto é, caracterizada pela facilidade de alcance massivo a determinados públicos, alcança o relato de si como instrumento fortalecedor da representação. Embora o alcance das redes sociais sejam, constantemente, um contra-discurso à cultura de massas, há de se considerar, conforme Miskolci (2011):

No Brasil, onde as classes médias (incluindo a classe $C$ ) chegam a mais de 100 milhões de pessoas, apenas 80 milhões têm acesso à internet. A diferença de cerca de vinte milhões, possivelmente, se deve a questões geracionais, nível educacional e local de moradia. $\mathrm{O}$ uso da rede é muito maior entre aqueles que nasceram ou chegaram à adolescência em meio à sua expansão comercial no final da década de 1990, portanto tendo mais chance e interesse de acionar seu uso para manter e/ou expandir suas relações sociais. Pessoas nascidas antes da década de 1970 já eram adultos com mais de 25 anos em 1997, portanto já haviam sido educados, socializados e constituído boa parte de seus vínculos sociais por outros meios. Não é de se estranhar que, para elas, a internet surgiu apenas como uma possibilidade extra de comunicação e foi incorporada de forma mais lenta e menos central em suas vidas (MISKOLCI, 2011, p. 11).

Dado ao recorte geracional, estes dispositivos discursivos aos quais homens transgêneros e transmasculinos estão inseridos são constituídos através da pluralidade 
de saberes sobre transgressão de gênero, a multiplicidade de "estágios" da transição e formação de distintas identidades. A transformação do corpo é um processo individual, embora a hormonização e intervenção cirúrgica seja desejo de um, mas não almejado por outro. São ambientes de exploração da identidade, de autodescoberta, de produção de conteúdo transespecífico que proporciona oportunidades para debater políticas públicas e enfrentar a violência. Promove a dignidade e desmistificação do estigma marginalizado, moldado no preconceito e deturpação da imagem hostilizada socialmente, fomentada pela mídia. Um controle monopolítico, um discurso de poder.

\begin{abstract}
Ao compartilhar suas rotinas, suas descobertas, suas fotos, seus vídeos, seus desabafos, seus relatos de experiências, suas denúncias de violência e preconceito vivenciados, suas histórias de amor, seus inúmeros links que redirecionam para sites de vendas de produtos específicos como próteses penianas e binders, o compartilhamento de matérias e notícias sobre outros transhomens ou sobre política eles ajudam a manter e fazer dos blogs uma fonte rica de informações sobre si, sobre os processos transexualizador dos transhomens e sobre a vida social dessa população. [...] Os blogs também ganham destaque quando possibilitam aos transhomens a chance de aproximação com pessoas das mais diversas partes do mundo que percorrem um caminho semelhante ao seu, uma chance de encontrar o reconhecimento de si nas histórias dos outros, uma chance de humanizar a sua própria história. Ainda que pesem algumas críticas sobre o que é exposto no ambiente virtual feitas, inclusive por alguns transhomens, a maioria dos usuários ainda atribui um número muito maior de benefícios do que de efeitos nocivos (AMORIM, 2016, p. 177).
\end{abstract}

Conforme mencionado pelo psicólogo Alexandre Amorim, em pesquisa sobre a escrita de si nos blogs, os transhomens, à medida que realizam o relato de suas experiências, todavia, são detentores deste conhecimento. O compartilhamento de informações nestes ambientes midiáticos produz um conhecimento contra-público (COACCI, 2018) que fomenta um lugar de aprendizado tanto para quem reproduz a informação, quanto para quem a recebe. É uma constante recíproca cujo relato de si transparece o reconhecimento do outro. Enquanto há produção do relato, há questionamento, revisão, reflexão e reinvenção. Enquanto há leituras do relato, há entendimento, aprofundamento, reconhecimento, ressignificação. Para tanto, o compartilhamento de sensações, emoções, memórias assim como descobertas no mergulho do passado, o emergir do presente, o confronto da moral e reorganização de si transformam, por sua vez, a dinâmica mútua da identificação de ambos, tanto o 
emissor, quanto o receptor da mensagem. Embora a representatividade seja condição para humanização, as narrativas representativas e histórias humanizadoras reelaboram protagonismos, fomentam resistências e atuam na promoção de visibilidade de sujeitos invisibilizados socialmente, na mídia e na vida.

\begin{abstract}
Teoria da dominação, das dominações, muito mais do que teoria da soberania, o que quer dizer: em vez de partir do sujeito (ou mesmo dos sujeitos) e desses elementos que seriam preliminares a relação e que poderíamos localizar, se trataria de partir da própria relação de poder, da relação de dominação no que ela tem de factual, de efetivo, e de ver como é essa própria relação que determina os elementos sobre os quais ela incide. Portanto, não perguntar aos sujeitos como, porque, em nome de que direito eles podem aceitar deixar-se sujeitar, mas mostrar como são as relações de sujeição efetivas que fabricam sujeitos. Em segundo lugar, tratar-se-ia de ressaltar as relações de dominação e de deixá-las valer em sua multiplicidade, em sua diferença, em sua especificidade ou em sua reversibilidade: não procurar, por conseguinte, uma espécie de soberania fonte dos poderes; ao contrário, mostrar como os diferentes operadores de dominação se apoiam uns nos outros, remetem uns aos outros, em certo número de casas se fortalecem e convergem, noutros casos se negam ou tendem a anular-se. Eu não quero dizer, é claro, que não há, ou que não se pode atingir nem descrever os grandes aparelhos do poder. Mas eu creio que estes funcionam sempre sobre a base desses dispositivos de dominação (FOUCAULT, 1999, p. 51).
\end{abstract}

Segundo Foucault (1999), a tônica emergente de mostrar como são as relações de sujeição que fabricam sujeitos são fundamentais para ressaltar as relações dominantes, a fim de elucidar como os operadores de dominação se apoiam, constantemente, uns nos outros. Desta forma, o controle hegemônico se utiliza de dispositivos midiáticos monopolíticos para demarcar, conforme Debord (2003), o espetáculo que constitui o modelo de vida socialmente dominante. A desestruturação da imagem desumana historicamente aplicada à patologização da transidentidade é, por sua vez, uma comunicação contra-hegemônica que visa desestabilizar as relações de sujeição que operam às camadas dominantes de estrutura heterocentrada, binariamente estimulantes na precarização de corpos trans em sua figuração subalternizada. Neste aspecto, o relato de si é, sobretudo, uma ferramenta política de resistência e subversão das relações de poder colonizadoras e embranquecidas impostas, tradicionalmente, pela mídia conservadora da massificação do objeto sensacionalista. Na espetacularização do espetáculo precário, cada vez mais, perdendo 
espaço no interesse do público, em detrimento da instauração das mídias digitais enquanto projeto de consumo.

\section{Considerações finais}

A produção de trabalhos acadêmicos e pesquisas científicas sobre transmasculinidade no Brasil tiveram início em meados dos anos 2000, sobretudo, quando o Conselho Federal de Medicina (Resolução CFM n.1.955/2010) instaurou a realização de procedimentos cirúrgicos direcionados especialmente aos homens trans/transmasculinos, no âmbito público e privado. Deste então, as transmasculinidades obtiveram maior visibilidade de produção acadêmica, na mídia e na cultura LGBT. Os transhomens ganharam espaço na pesquisa científica através de um entendimento social do sujeito político, em um espaço delimitado anteriormente apenas às travestis e mulheres transexuais, principalmente, no que está relacionado à saúde pública e redesignação sexual. A Resolução CFM n.1.955/2010 permite que os homens trans sejam percebidos socialmente diante da invisibilidade estrutural de suas identidades.

No âmbito da mídia e cultura LGBT, as transmasculinidades se tornam mais visíveis na diversidade transgênera, em pautas específicas na saúde pública e pluralidade de composições do masculino. A transexualidade se tornou pauta mais acessível e discutida culturalmente. No entanto, há conhecimentos precarizados sobre pessoas trans, no que se refere a inexistência de dados sobre evasão escolar, sobre violências e mortes de pessoas trans, além de informações estruturais sobre a vida destas identidades na aplicação de políticas públicas transespecíficas. Para suprir este conhecimento precário, a pesquisa acadêmica tenta, por sua vez, articular a transformação social na produção de conhecimento, difusão de saberes e tensionamento de políticas públicas e inclusão social.

Este artigo tem por objetivo tratar, de modo breve, a "representatividade" em um olhar amplificado de sua configuração "imagética”, sobretudo, no que concerne a identidade transgênera em representação político-social, seja no conhecimento científico, na produção de conteúdo nas multimídias, no relato de si à luz de 
visibilidade para suas existências, na personificação da mídia, televisão, cinema, literatura, publicidade, entre muitas possibilidades de transativismo representativo. A exemplo de influência digital, cuja relação de poder sobre opinião e consumo atribuído às câmeras multimidiáticas são capazes de influenciar o comportamento do espectador que acompanha estes canais de "estilo de vida virtual".

Desta forma, há muitos homens trans e transmasculinos que adentram essas redes digitais na promoção de visibilidade para seus corpos, na possibilidade de demarcar diálogos através do entretenimento para desmistificação de conteúdos precarizados sobre transidentidades. A transposição de assuntos ligados a gênero, sexo, sexualidade, transição, feminismo, raça e etnia nas mídias digitais reaproximam indivíduos que possuem estas temáticas como interesse particular. Para tanto, há pessoas interessadas no aprendizado desses conteúdos bem como outras que dão lugar às suas redes pessoais para proporcionar visibilidade a sujeitos marginalizados socialmente. O conteúdo “desprivilegiado" pelo "alcance popular das redes" possui oportunidade de comunicação para os demais perfis compartilhados, na ótica contrahegemônica do controle da informação.

É importante mencionar que, neste percurso midiático cujos homens trans/masculinos estão inseridos, há um alcance viável para outras plataformas de mídias, seja na publicidade e propaganda, seja na televisão, em podcast, em entrevistas de blogs, vídeos na internet, filmes e séries, bem como na visibilidade científica de pessoas transgêneras na academia, na produção de conhecimento tanto sobre gênero, sexualidade, quanto temáticas afins, sobretudo, pesquisadores e intelectuais. A representatividade de homens transgêneros, assim como na autobiografia de João W. Nery $(1984,2011)$ e sua visibilidade fundamental na vida de outros homens trans e pessoas transgêneras que se espelham em sua trajetória, demarcam a caminhada de sujeitos que vivem sua viagem solitária em um itinerário acompanhado. A representatividade na demonstração de que pessoas trans são elegíveis para falar sobre si, bem como podem e devem ocupar espaços cujo direito é assegurado democraticamente, por sua vez, abrem caminhos para que outras pessoas transgêneras sigam conquistando seus lugares no mundo. Sobretudo, reconstruindo suas histórias ao desconfigurar a subalternidade imposta. 


\section{Referências}

ALMEIDA, Guilherme. 'Homens trans': novos matizes na aquarela das masculinidades? Revista Estudos Feministas, v. 20, n. 2, p. 256-266, 2012.

ANTRA. Associação Nacional de Travestis e Transsexuais. Disponível em: $<$ https://antrabrasil.org/>. Acesso em: 20 abr. 2020.

AMORIM, Alexandre. Homens (In)visíveis: a experiência de transhomens brasileiros nas mídias virtuais. Dissertação (Mestrado) - Universidade Federal de Santa Catarina. Centro de Filosofia e Ciências Humanas. Programa de Pós-Graduação em Psicologia, Florianópolis, 2016.

ÁVILA, Simone. FTM, transhomem, homem trans, trans, homem: A emergência de transmasculinidades no Brasil contemporâneo. 2014. 243f. Tese (Doutorado Interdisciplinar em Ciências Humanas) - Universidade Federal de Santa Catarina, Centro de Filosofia e Ciências Humanas. Florianópolis, SC, 2014.

BUTLER, Judith. Corpos que pesam: sobre os limites discursivos do "sexo". In: LOURO, Guacira Lopes. (Org.). O corpo educado - Pedagogias da sexualidade. Belo Horizonte: Autêntica Editora, 2010. p. 110-126.

Problemas de gênero - feminismo e subversão da identidade. Rio de janeiro: Civilização Brasileira, 2003a.

. Relatar a si mesmo - Crítica da violência ética. Belo Horizonte: Autêntica Editora, 2015a.

. Vida precária: Contemporânea - Revista de Sociologia da UFSCar. São Carlos, Departamento e Programa de Pós-Graduação em Sociologia da UFSCar, 2011, n.1, p - 1333 .

Quadros de guerra - Quando a vida é passível de luto? Rio de Janeiro: Civilização Brasileira, 2015b.

CARDOSO. R. O. O trabalho do antropólogo: Olhar, ouvir, escrever. In: O Trabalho do

Antropólogo. São Paulo/Brasília: EdUNESP/ Paralelo 15, 2000.

COACCI, Thiago. Conhecimento precário e conhecimento contra-público [manuscrito]: a coprodução dos conhecimentos e dos movimentos sociais de pessoas trans no Brasil / Tese (doutorado) - Universidade Federal de Minas Gerais, Faculdade de Filosofia e Ciências Humanas. Thiago Coacci. - 2018. 
DEBORD, Guy. Sociedade do espetáculo. Projeto Periferia, 2003.

FOUCAULT, Michel. Em defesa da sociedade. Curso no Collège de France (19751976). Tradução Maria Ermantina Galvão. São Paulo: Martins Fontes. 1999. - (Coleção Tópicos).

A História da Sexualidade 1. A vontade de Saber. 1988. Edições Graal. Tradução: Maria Thereza da Costa Albuquerque e J. A. Guilhon Albuquerque.

FREITAS, Renata. Homens com T maiúsculo: processos de identificação e construção do corpo nas transmasculinidades e a transversalidade da internet. 2014. 121f. Dissertação (Mestrado em Psicologia). Universidade Federal de Minas Gerais, 2014.

LANZ, Letícia. O corpo da roupa: A pessoa transgênera entre a conformidade e a transgressão das normas de gênero. Uma introdução aos estudos transgêneros. Curitiba: Transgente, 2015.

MISKOLCI, R. Novas conexões: notas teóricometodológicas para pesquisas sobre o uso de mídias digitais. Cronos, v. 12, n. 2, p. 09-22, 2011.

NERY, João. W.; MARANHÃO FILHO. Eduardo. Transhomens no ciberespaço: micropolíticas das resistências. História Agora, v. 16, n. 2, p. 6o-80, 2013.

Erro de pessoa. Rio de Janeiro: Record, 1984.

. Viagem Solitária - Memórias de um transexual trinta anos depois. São Paulo: Leya, 2011.

. De viagem solitária ao ativismo. Texto parcial da palestra apresentada durante $07^{\mathbf{o}}$ Seminário Internacional de Bibliotecas Públicas e Comunitárias em novembro de 2014. Disponível em: <http://siseb.sp.gov.br/arqs/INT_DE_VIAGEM_SOLITARIA_AO_ATIVISMO_Joao\%20 Walter\%2oNery.pdf $>$. Acesso 11/o6/2020.

ORGANIZAÇÃO MUNDIAL DA SAÚDE. Classificação de Transtornos Mentais e de Comportamento da CID 1o: descrições clínicas e diretrizes diagnósticas. Porto Alegre: Artes Médicas, 1993.

RIBEIRO, Djamila. O que é lugar de fala? Belo Horizonte: Letramento, Justificando, 2017.

SILVA, Tomaz. A produção social da identidade e da diferença. In: SILVA, Tomaz Tadeu da Silva; HALL, Stuart; WOODWARD, Kathryn; Identidade e Diferença: a perspectiva dos Estudos culturais. 12 ed. Petrópolis, RJ: Vozes, 2012. 